BLS 33, No 1 2007. DOI: http://dx.doi.org/10.3765/bls.v33i1.3547

(published by the Berkeley Linguistics Society and the Linguistic Society of America)

\title{
Creole Phonology: An Alternative to Markedness-Based Accounts
}

\author{
WHITNEY WARD \\ Yale University
}

\section{The Role of Markedness in Creole Phonology}

A central question in the field of creole studies concerns whether creole grammars reflect the emergence of language universals during creolization ("universalist" accounts) or if they closely replicate the grammars of the substrate languages from which they emerge ("substratist" accounts) (see Arends et al. 1994 for a distilled account of theoretical approaches to creolization). The problem has been most considered in creole syntax, but with the development of Optimality Theory (Prince and Smolensky 1993), which places a special emphasis on universal phonological markedness, this debate has expanded into the field of creole phonology (e.g. Alber and Plag 2001, Lipski 2002, Uffmann 2003, Singler 2000). These markedness-based explanations of the creolization of phonology are somewhat problematic, however, and this paper will offer an alternative to such explanations.

Optimality Theoretic analyses have been used in support of both universalist and substratist accounts of creolization. What these accounts have in common is the assertion that differences between creole and superstrate phonologies are the result of the promotion of markedness constraints during creolization. Proponents of universalist accounts assert that creoles represent the "emergence of the unmarked" during creolization. Because high ranked markedness is considered to be a sort of phonological default and the lack of language data during creolization results in the inability to promote all of the appropriate faithfulness constraints, the result of creolization is a less universally marked phonology than that of any of the input grammars. Proponents of substratist accounts, however, argue that the African languages that are the most common creole substrates are phonologically unmarked in the same ways as many creoles. Substratists suggest that the apparent "emergence of the unmarked" is due to the application of substrate constraint rankings to superstrate lexical items, and not to any universal tendency towards high-ranked markedness.

Despite its central role in Optimality Theory, the use of typological markedness as an explanatory mechanism in synchronic phonology has been 


\section{Whitney Ward}

criticized both because using typological rarity as the formal basis for explaining that rarity is circular, and because markedness is often epiphenomenal; the actual explanation for the preference of some sound patterns is due to (arguably) extragrammatical factors like perceptibility or tendencies of diachronic change (e.g. Haspelmath 2006, Blevins 2004). Beyond the general problems with the use of markedness as an explanatory mechanism in phonology, the specific use of highranked markedness in explaining phonological changes that occur during creolization is problematic for a number of reasons. First, both substratist and universalist theories have difficulty when the ranking of faithfulness constraints is needed in the creole grammar to dictate which repair strategies are used to avoid marked structures. This would not be problematic if each creole used only a single repair strategy to resolve a non-optimal structure (always using epenthesis to resolve consonant clusters, for instance) but analyses of actual creole data show that this is not the case. Since there is not a universal ranking of faithfulness constraints, and substrate speakers do not encounter markedness violations in their own languages that would provide evidence of faithfulness constraint ranking, markedness-based theories have difficulty explaining the choice of different repair strategies to resolve the same marked structure.

Universalist accounts are also problematic in that they may require that markedness constraints be internally ranked. For example, though there is a tendency for creoles to prefer CV syllables (e.g. Sebba 1997), which are the least marked syllable type (Blevins 1995), there are often a variety of other acceptable syllable types as well. If creolization is the promotion of markedness, it is not clear why some marked structures are eliminated and others are allowed to remain. Uffmann (2003) avoids this problem in his more limited universalist account, suggesting that high ranked markedness is the result of substrate leveling, a process that selects the least marked of the possible substrate grammars as the basis for the creole. Like Uffmann's model, substratist accounts do explain the origin of markedness constraint rankings (they are taken directly from the substrate). However, these models cannot explain why creole phonologies are often not identical to those of their substrates.

\section{The Alternative Account}

\subsection{Three Factors that Shape Creole Phonology}

The alternative account presented here characterizes creolization as a process of rapid sound change occurring because of imperfect second language acquisition. Differences between the superstrate and creole phonologies result from three factors that reflect this characterization of the creolization process: cue robustness and segment perceptibility, perception of substrate forms by second language learners, and production of these forms when they are correctly perceived. The first of these factors will lead to the apparent favoring of universally "unmarked" structures while the latter two explain the resemblance of creole and substrate phonological patterns. This account is motivated by the observation that the phonological changes which occur during creolization resemble listener-initiated 


\section{Creole Phonology}

sound changes in non-contact situations as well as changes that occur during second language acquisition and borrowing. Creolization of phonology, in this view, is a set of sound changes driven by a group of non-native speakers.

\subsection{Gradualism and Creolization as Second Language Acquisition}

This proposal is closely aligned theoretically with accounts that treat creolization as a special case of second language acquisition (SLA). Though the SLA hypothesis has been discussed with relation to the syntactic features of creoles (for an overview see Mather 2006) it has not been widely used to account for creolization in phonology. Creolization differs from normal second language acquisition in that access to native speakers of the target language is limited. This target language is also being used as the primary language of communication among speakers who speak neither the same L1 (substrate) nor the L2 (superstrate). Proposals that treat creolization as SLA differ from the standard descriptions of creole languages as nativized pidgins formed in a single generation. Instead, creolization is claimed to be a gradual process, carried out primarily by adult speakers. Though there are advocates of both the single generation and gradualist accounts of creolization, gradualist proponents suggest demographic evidence shows that some plantation creoles (specifically the creoles of Surinam and Jamaica) were in existence before a large number of children could have acquired the creole natively. In some of these cases imported substrate speakers vastly outnumbered native creole speakers during the time of creolization (Arends et al. 1994, Arends 1995). These demographic factors suggest that creolization may have occurred gradually and been driven by adult speakers attempting to acquire the superstrate as a second language.

\subsection{Cue Robustness and Perceptibility}

Each of the three factors that explain the phonological changes that occur during creolization has been observed in other areas of linguistics. Cue robustness and segment perceptibility have been used to ground markedness constraints and explain phonotactic restrictions. Previous work on the perceptibility of contrasts has shown that phonotactic constraints can often be explained by general principles of segment perceptibility (e.g. Wright 2004, Blevins 2003, Steriade 1999). The segments that are most easily perceived in particular positions are also those that are most likely to be preserved during creolization. Phonological changes related to this factor that occur during the creolization process are also similar to those observed during listener initiated sound change (Ohala 1993) and as part of the program of Evolutionary Phonology (Blevins 2004). Changes of this type need not depend on the nature of the substrate language, which allows this model to account for many of the phonological characteristics of creoles that do not appear to be taken directly from the substrate languages.

\subsection{Second Language Perception and Production}


Whitney Ward

The second factor shaping creole phonology, the perception of contrasts by second language speakers, has also been discussed outside of the creole liturature. Previous work has shown that the phonological structure of L1 can affect listeners' perceptions of L2 leading to perceptual epenthesis (Dupoux et al. 1999, Kabak 2003) or the reshaping of phonological categories (Khul 1991, Best 1994) among other segmental and phonotactic changes. Because early creole speakers are second language learners, their perceptions of the superstrate will be shaped by their own (substrate) phonology. Changes that occur during creolization could be the result from the misparsing of superstrate forms in a way that conforms to the linguistic expectations of substrate speakers.

The final factor that influences the creolization process is the production of contrasts by early creole speakers. Even when phonological contrasts are perceived correctly, they may not be reproduced accurately by second language learners. Davidson $(2006,2007)$, for example, has shown that gestural mistiming can result when L2 speakers attempt to produce non-native consonant clusters. The fact that creoles are created through perception and production of a language by adult learners can account for substrate influence on creole phonology. The three factors taken together offer explanations for the major features of creole phonologies without the use of high ranked markedness as an explanatory mechanism.

\section{Comparing the Accounts: A Case Study of Sranan 3.1 History of the Sranan Language}

This approach has advantages when compared to previous markedness-based accounts of creole phonology. First, it avoids the general criticisms of the use of markedness as an explanatory device. Secondly, it provides an account of phenomena that are difficult to explain using other accounts. This can be exemplified through a close examination of the syllable structure of Sranan, an English based creole that emerged in the middle of the $17^{\text {th }}$ century in Surinam and is still spoken there today. The primary substrate languages are the Bantu language Kikongo and the Kwa languages Gbe and Twi (although, importantly, Twi speakers were not brought to Suriname until after English speakers were no longer present). The history of colonization in Surinam suggests gradual creolization was the likely path of development for Sranan. English settlers were present in the colony only from approximately 1651 to 1690 (the Dutch occupied the colony from 1680 until the late $20^{\text {th }}$ century). A pidgin version of Sranan must have formed during this short period of exposure to English. Both during and after this period of colonization by English speakers, new slaves were being brought to the island in very large numbers (Arends 1995). The poor treatment of slaves in Surinam (even by the standards of the time) and difficult conditions in the colony led to a very high mortality rate and a need to introduce new slaves constantly. For the same reason, very few children were born in Surinam during the time the creole was being formed. Sranan is an ideal case study here because data is available from the early stages of creolization (before restructuring and contact 


\section{Creole Phonology}

with Dutch) and because Alber and Plag (2001) already provide an overview and Optimality Theoretic account of Sranan phonology. These authors describe a number of processes that apply to English words when they were adapted into Sranan. Processes of deletion and epenthesis conspire to result in an apparent preference for CV syllables in this creole.

\subsection{The Emergence of the CV Syllable in Sranan \\ 3.2.1 Word Initial Deletion}

The first process that results in the restructuring of English syllables is deletion of word initial [s] where it occurs as part of a complex onset with a stop. Some examples are given in (1) below.

$\begin{array}{lll}\text { speak } & > & \text { piki } \\ \text { spoil } & > & \text { pori } \\ \text { stand } & > & \text { tan } \\ \text { story } & > & \text { tori } \\ \text { strong } & > & \text { tranga } \\ \text { square } & > & \text { kweri } \\ \text { scratch } & > & \text { krasi }\end{array}$

The examples in (2) demonstrate that [s] is preserved in initial [s] + nasal clusters.

$$
\begin{array}{lll}
\text { smoke } & > & \text { smoko } \\
\text { snake } & > & \text { sneki }
\end{array}
$$

Alternative strategies of epenthesis or deletion of the second consonant in these sequences are not observed. Somewhat different strategies are applied to word internal and word final consonant clusters, however.

\subsubsection{Word Internal Deletion}

Word internally, clusters are simplified either by deletion of the first or second element in the cluster as shown in (3).

$\begin{array}{lll}\begin{array}{l}\text { doctor } \\ \text { goodnight }\end{array} & > & \begin{array}{l}\text { datra } \\ \text { kuneti }\end{array} \\ \text { master } & > & \text { masra } \\ \text { nasty } & > & \text { nasi } \\ \text { softly } & > & \text { safri } \\ \text { sister } & > & \text { sisa }\end{array}$

If the word internal consonants are a series of two stops, or a stop followed by a nasal, the first stop is deleted. However, if the cluster is a fricative followed by a stop, the fricative is preserved and the stop is deleted. Further data presented in 


\section{Whitney Ward}

(4) shows that clusters of nasal followed by stop are preserved (data is adapted from Herlein 1718 and Nepveu 1770, two texts included in Arends and Perl 1995).

$\begin{array}{lll}\text { windows } & > & \text { windels } \\ \text { handsome } & > & \text { hansum } \\ \text { sometime } & > & \text { somtem }\end{array}$

\subsubsection{Word Final Cluster Simplification}

In final position, clusters are simplified by deleting the second segment in the cluster (unless the first element is a nasal) as shown in (4). In the later development of Sranan, the NC clusters are also reduced by the deletion of the stop, but in the earliest stages these stops are preserved.

$\begin{array}{lll}\text { field } & > & \text { firi } \\ \text { first } & > & \text { fosi } \\ \text { haste } & > & \text { hesi } \\ \text { soft } & > & \text { safu } \\ & & \\ \text { want } & > & \text { wanti } \\ \text { paint } & > & \text { pendi }\end{array}$

\subsubsection{Word-final Epenthesis}

As is apparent above, there is also a process of word final epenthesis. Words ending in non-nasal consonants take an epenthetic final vowel. More examples are given in (6) below.

$\begin{array}{lll}\text { afraid } & > & \text { freed } \\ \text { because } & > & \text { bikasi } \\ \text { nose } & > & \text { noso } \\ \text { top } & > & \text { tapu }\end{array}$

Final nasals trigger neither deletion nor epenthesis as exemplified in (7).

$\begin{array}{lll}\text { begin } & > & \text { begin } \\ \operatorname{man} & > & \text { man } \\ \text { name } & > & \text { nen } \\ \text { time } & > & \text { ten } \\ \text { sometime } & > & \text { somtem }\end{array}$

The authors note that final [y] does trigger epenthesis, though no examples of this type are given.

\section{An Existing Markedness Based Account of the Syllable in Sranan}




\section{Creole Phonology}

Alber and Plag (2001) argue that the syllable structure of Sranan is the result of transfer from the substrate languages and, using an OT framework, they treat the creolization process as one of massive borrowing. Words from the lexifier language are taken as the input to the grammar of the substrate language. The output strives to be faithful to the English input but not violate the markedness constraints that are highly ranked in the substrate grammars. In this particular case, the authors provide an analysis using the constraints in (8) with the constraint ranking in (9).

CODA COND: Only nasals are possible codas

SSP: Sonority must increase toward the syllable peak

NO SKIP: No internal deletion

NO INTRUDE: No internal epenthesis

MAX: No deletion

DEP: No Epenthesis

$$
\text { SSP, CODA COND, No INTRUDE }>>\text { MAX, NO SKIP >> DEP }
$$

If the authors' hypothesis is correct, this ranking should be present both in the grammar substrate and creole grammar. They do demonstrate that this ranking can account for the Sranan data shown above. First, the ranking of CODA COND and MAX over DEP can account for word final epenthesis. Coda obstruents are not allowed, and the best repair is to insert a final vowel. Coda nasals do not cause a violation and are allowed to remain. The high rank of SSP causes clusters of [s] followed by a stop to be non-optimal and can account for word initial deletion. Initial deletion is preferred as a repair strategy because the constraints against internal epenthesis or deletion are highly ranked. Because of this, the best repairs will occur at edges, and only deleting the initial [s] is optimal. Final deletion reflects the mirror image of this process, so in word final clusters the second of two consonants is deleted (this occurs along with final epenthesis).

Internal clusters prove slightly more complicated. The ranking provided has two optimal candidates. For example, the word "nasty" could result in either [na.ti] or [na.si]. In either case, only a single consonant is deleted, resulting in one violation of NO SKIP and one violation of MAX. Epenthesis is dispreferred due to the higher ranking of NO INTRUDE and the faithful form violates either CODA COND or the SSP. The authors believe that there may be a constraint that causes the least sonorous consonant to be deleted, but they do not attempt to include this constraint in their model. Despite this lack of a complete explanation for internal cluster simplification, this ranking provides a fairly straightforward analysis of the Sranan data. The type of syllable that is allowed by these constraints is also quite close to the syllable type allowed by the two early substrate languages.

Despite the successes of some portions of this analysis, the Sranan example demonstrates that difficulties arise when creolization is simply treated as relexification of the substrate grammar. The first problem arises in explaining 
Whitney Ward

mismatches between the creole grammar and the grammars of the major substrate languages. Alber and Plag point out in a footnote that this problem exists for their analysis of Sranan. There are no nasal codas in either Gbe or Kikongo, the two major substrate languages of Sranan (these codas are allowed in Twi, but speakers of this language did not arrive in Surinam until late in the development of the creole, and nasal codas were already present in the language before their arrival). Nasal codas do occur in the creole, despite their absence in the substrate languages. In order for the pure substratist account to explain this, it must be assumed that the constraint CODA COND, which prohibits obstruent codas but not nasal ones, must be highly ranked, while a more general constraint banning all codas must not be. This seems unlikely to be the case in the substrate grammars since there is no evidence from these languages that codas of any type are permitted.

The second general problem with the substratist account (also noted by the authors) is that substrate languages do not have alternations that provide evidence for the ranking of faithfulness constraints. Since speakers of these languages never come in contact with violations of the high ranked markedness constraints, there should be no evidence that one type of repair strategy is preferred over another. This seems especially problematic for a complex analysis like the one provided for Sranan, because the same repair strategy is not always preferred. Four faithfulness constraints must be ranked correctly in order for the appropriate grammar to emerge in this creole, and different rankings are required for word internal clusters and clusters at edges. Why should such differences be present in substrate grammars when speakers of these languages are never provided with evidence for the ranking of faithfulness?

\section{Applying the Alternative: The Three Factors in Sranan}

The three factors proposed above can account for the phonological changes observed in Sranan while avoiding the problems encountered by the markednessbased approach. Each of the changes that result in the syllable structure of Sranan can be explained by some combination of these factors. First, word internal clusters that do not include fricatives are resolved by deletion of the first of the two consonants $(\mathrm{C} 1 \mathrm{C} 2>\mathrm{C} 2)$. Perceptual factors can account for this type of change, which is also observed in normal sound change. In English, word internal consonants show a large degree of overlap (Zsiga 2000). Because of this, the first of two adjacent consonants is not released into a vowel so formant transition and burst cues for this consonant are not robust. The obscuring of these cues increases the likelihood that only the second of the two consonants will be perceived. Listeners who have little experience with heavily overlapped consonant clusters may have greater difficulty in identifying two consonants from the percept of a single closure and a single release. This also explains the perhaps unexpected preservation of nasals in medial clusters. Because the cues for nasal manner are robust throughout the consonant closure, not just at the release into a vowel, nasals are perceived more easily even in overlapping clusters. Cue robustness, 


\section{Creole Phonology}

along with substrate speakers' limited experience perceiving overlapped consonants, can explain the behavior of these clusters without the use of markedness constraints.

Unlike medial codas, which are repaired through deletion, final codas are repaired by epenthesis of a final vowel. In borrowing and second language acquisition, as well as normal sound change, epenthesis can result from the misinterpretation of a final stop burst as an intended final vowel (e.g. Kang 2004). The perception of English final stops by substrate speakers might result in similar perceptual epenthesis. A slightly problematic aspect of this analysis is that epenthesis in Sranan also occurs after the fricative [s], which, unlike stop consonants, does not have a release burst. However, I speculate that the offset of frication at the end of a word final [s] may also have burst like properties and could be interpreted as a vowel. The similar behavior of stops and fricatives in triggering epenthesis is not limited to Sranan as both consonant types also trigger perceptual epenthesis in Japanese (Dupoux et al. 1999). The use of different strategies to eliminate codas in medial and final positions is explained by the differences in perceptibility of segments in these positions. Because medial codas occur in overlapped clusters, there is not a strong burst to be misinterpreted as an epenthetic vowel in that position. The perception of medial and final codas will be different and can explain the differing behavior of codas without the need for unmotivated ranking of multiple faithfulness constraints.

The preservation of final nasal (and liquid) codas can also be explained in this account. Because nasals have no burst that could be misinterpreted as an epenthetic vowel, epenthesis does not occur following nasals. The changes in nasal place shown in example (7) (reproduced below) can also be attributed to perceptual factors.

$\begin{array}{lll}\text { name } & > & \text { nen } \\ \text { time } & > & \text { ten }\end{array}$

Though cues for nasal manner are robust even in final position, cues for nasal place occur mostly at the CV transition. Given this, changes in place features in coda position may be expected during creolization.

Consonant clusters in final position are resolved by both the deletion of the second consonant and epenthesis of a final vowel. Because epenthesis is the result of misinterpretation of a stop burst, the loss of $\mathrm{C} 2$ is unlikely to be the result of the listeners' inability to perceive the burst cues for this stop. The reason for this cluster reduction may instead be the speakers' inability to produce coda clusters as native speakers do. Browman and Goldstein (2000) have shown that the coordination of oral articulator gestures in coda position is more difficult than gestural coordination in onset position. Substrate speakers who have no experience with coda clusters may be unable to replicate this coordination pattern. The preservation of homorganic nasal + stop clusters in this position could result from the need to coordinate only the velum gesture (which substrate speakers 


\section{Whitney Ward}

already must do in order to produce single nasal consonants), as only a single oral articulation is needed for such clusters. Experimental evidence has shown that gestural mistiming often results when speakers attempt to produce non-native consonant clusters and the effects of this can be observed in loan word adaptation.

One aspect of Sranan phonology that is difficult to explain in either of the accounts discussed here is the behavior of [s] + stop clusters. Initial clusters of this type are repaired through the deletion of [s] while initial $[\mathrm{s}]+$ sonorant clusters are preserved. Medial fricative + stop clusters, however, are resolved through the deletion of the second consonant $(\mathrm{C} 1 \mathrm{C} 2>\mathrm{C} 1)$. This differs both from initial [s] clusters and other medial clusters. Alber and Plag argue that word initial clusters simplify only if they violate the SSP and they contend that [s] + stop clusters cause such a violation. Though this may be the case given some form of the SSP, Wright (2004) and others have suggested that sibilant fricatives often form fricative + stop clusters and that these clusters are not typologically marked. Because of this, the elimination of these clusters based on high ranked markedness is problematic. The ranking provided by Alber and Plag cannot account for this systematically differing behavior of internal clusters.

It is also somewhat difficult to account for the behavior of these [s] clusters using perceptual and production based explanations. The cues for sibilant fricatives are robust throughout the consonant closure, so misperception of these segments is unlikely. The inability of substrate speakers to replicate gestural coordination in obstruent + obstruent clusters could explain the loss of [s] in initial position. The substrate languages allow obstruent + sonorant clusters, so the proper coordination for [s] + nasal clusters should already be available to creole learners. However, it could be the case that coordination for each type of cluster must be learned separately. Perceptual factors also cannot easily explain the behavior of internal [s] clusters since cues for [s] and C2 should both be robust in this position. Most of the examples given for this type of cluster are [s] + [t] sequences. It could be the case that coordinating these two segments, which both involve tongue tip gestures but have different specifications for tongue position, is particularly difficult for L2 speakers. It is also possible that the [t] is

perceived as a transitional element instead of an intended full consonant and thus not reproduced by creole speakers. These explanations are preliminary, however, and the behavior of [s] clusters remains somewhat problematic in both accounts.

\section{Conclusion}

The case study of Sranan demonstrates that an appeal to perceptual and production related factors offers a viable alternative to markedness promotion in accounting for phonological restructuring during creolization. This account also avoids the problems inherent in the use of markedness as an explanatory mechanism in phonology. An appeal to the three factors described above provides an explanation of the use of multiple "repair strategies" in creolization and allows for the influence of both universal and substrate factors. This account also relates the phonological changes observed during creolization to similar changes attested 


\section{Creole Phonology}

in normal diachronic change and second language acquisition. Continuing typological and experimental work on creole phonology may provide more support for such alternatives to markedness in explaining the creolization process.

\section{References}

Alber, Birgit and Ingo Plag. 2001. Epenthesis, Deletion and the Emergence of the Optimal Syllable in Creole: The Case of Sranan. Lingua 111: 811-840.

Arends, J. and M. Perl. 1995. Early Suriname Texts: A Collection of Early Sranan and Saramaccan Documents. Frankfurt: Vervuert.

Arends, Jacques, Pieter Muysken, and Norval Smith, eds. 1994. Pidgins and Creoles: An Introduction. Philadelphia: John Benjamins Publishing.

Best, Catherine T. 1994. The Emergence of Native-Language Phonological Influences in Infants: A Perceptual Assimilation Model. In J. Goodman and H. Nusbaum, eds. The Development of Speech Perception: The Transition from Speech Sounds to Spoken Words, 167-224. Cambridge, MA: MIT Press.

Blevins, Juliette. 1995. The Syllable in Phonological Theory. In J.A. Goldsmith ed., The Handbook of Phonological Theory, 206-244. Cambridge, MA: Basil Blackwell.

Blevins, Juliette. 2004. Evolutionary Phonology. Cambridge: Cambridge University Press.

Blevins, Juliette. 2003. The Independent Nature of Phonotactic Constraints: An Alternative to Syllable-Based Approaches. In C. Fery and R. van de Vijver eds, The Syllable in Optimality Theory. New York: Cambridge University Press.

Browman, Catherine and Louis Goldstein. 2000. Competing Constraints on Intergestural Coordination and Self-Organization of Phonological Structures. Les Cahiers de l'ICP, Bulletin de la Communication Parlee 5:25-34.

Davidson, Lisa. 2006. Phonotactics and Articulatory Coordination Interact in Phonology: Evidence from Non-Native Production. Cognitive Science 30(5):837-862.

Davidson, Lisa. 2007. The Relationship Between the Perception of Non-Native Phonotactics and Loanword Adaptation. To appear in Phonology.

Dupoux, Emmanuel, Kazuhiko Kakehi, Yuki Hirose, Christophe Pallier, and Jaques Mehler. 1999. Epenthetic Vowels in Japanese: A Perceptual Illusion. Journal of Experimental Psychology: Human Perception and Performance 25:1568-1578.

Haspelmath, Martin. 2006. Against Markedness (and What to Replace it With). Journal of Linguistics 42:25-70.

Kabak, Baris. 2003. The Perceptual Processing of Second Language Consonant Clusters. Ph.D. diss., University of Delaware.

Kang, Hyun-Sook. 2004. Perceptual Similarity in Loanword Adaptation: English Postvocalic Word-Final Stops in Korean. Phonology 20:219-273. 


\section{Whitney Ward}

Kuhl, Patricia K. 1991. Human Adults and Human Infants Show a 'Perceptual Magnet Effect' for the Prototypes of Speech Categories, Monkeys Do Not. Perception \& Psychophysics 50:93-107.

Lipski, John M. 1992. Epenthesis vs. Elision in Afro-Iberian Language. In T. Satterfield, C. Tortora, and D. Cresti eds., Current Issues in Romance Languages, 173-188. Philadelphia: John Benjamins Press.

Mather, Patrick-Andre. 2006. Second Language Acquisition and Creolization: Same (i-) Process, Different (e-) Results. Journal of Pidgins and Creoles 21(2):231-274.

Ohala, John J. 1993. The Phonetics of Sound Change. In C. Jones, ed., Historical Linguistics: Problems and Perspectives, 237-278 New York: Longman.

Prince, Alan and Paul Smolensky. 1993. Optimality Theory: Constraint Interaction in Generative Grammar. Rutgers Optimality Archive 537.

Sebba, Mark. 1997. Contact Languages. New York: St. Martins Press.

Singler, John Victor. 2000. Optimality Theory, the Minimal Word Constraint, and the Historical Sequencing of Substrate Influence in Pidgin/Creole Genesis. In J. McWhorter, ed., Language Change and Language Contact, 335-352. Philadelphia: John Benjamins Press.

Steriade, Donca. 1999. Alternatives to the Syllabic Interpretation of Consonantal Phonotactics. In O. Fujimura, B. Joseph, and B. Palek eds., Proceedings of the 1998 Linguistics and Phonetics Conference, 205-242. Prague: The Karolinum Press.

Uffmann, Christian. 2003. Markedness, Faithfulness and Creolization: The Retention of the Unmarked. In I. Plag ed., Phonology and Morphology of Creole Languages. Tubingen: Max Neimeyer Verlag.

Wright, Richard. 2004. A Review of Perceptual Cues and Cue Robustness. In B. Hayes, R. Kirchner, and D. Steriade eds., Phonetically Based Phonology. New York: Cambridge University Press.

Zsiga, Elizabeth C. 2000. Phonetic Alignment Constraints: Consonant Overlap and Palatalization in English and Russian. Journal of Phonetics 28:69-102.

Whitney Ward

Yale University

Department of Linguistics

370 Temple Street, Room 204

New Haven, CT 06520

whitney.ward@yale.edu 